\title{
High-Energy X-Ray Microprobe System with Submicron Resolution for X-Ray Fluorescence Analysis of Uranium in Biological Specimens
}

\author{
Yasuko Terada, ${ }^{1}$ Shino Homma-Takeda, ${ }^{2}$ Akihisa Takeuchi, ${ }^{1}$ and Yoshio Suzuki ${ }^{1}$ \\ ${ }^{1}$ Japan Synchrotron Radiation Research Institute, SPring-8, 1-1-1 Kouto, Sayo, Hyogo 679-5198, Japan \\ ${ }^{2}$ Research Center for Radiation Protection, National Institute of Radiological Sciences, 4-9-1 Anagawa, Inage-ku, \\ Chiba 263-8555, Japan
}

Correspondence should be addressed to Yasuko Terada, yterada@spring8.or.jp

Received 3 November 2009; Accepted 21 May 2010

Academic Editor: Gene Ice

Copyright () 2010 Yasuko Terada et al. This is an open access article distributed under the Creative Commons Attribution License, which permits unrestricted use, distribution, and reproduction in any medium, provided the original work is properly cited.

\begin{abstract}
Total-external-reflection Kirkpatrick-Baez mirror optics for high-energy X-rays have been applied to the X-ray microprobe at beamline 37XU of SPring-8. A focused beam size of $1.0 \mu \mathrm{m}(\mathrm{V}) \times 0.83 \mu \mathrm{m}(\mathrm{H})$ has been achieved at an X-ray energy of $30 \mathrm{keV}$, and a total photon flux of the focused beam was about $5 \times 10^{9}$ photons/s. Micro-X-ray fluorescence $(\mu$-XRF) analysis of the uranium distribution in rat kidneys has been performed with the mirror-focused beam. The sensitivity of uranium was evaluated from the XRF intensity of thin standard samples, and the minimum detection limit was estimated at $10 \mu \mathrm{g} / \mathrm{g}$. The high-spatial-resolution analysis revealed that uranium was concentrated in the epithelium of the proximal tubules in the inner cortex. The maximum concentration of uranium in the tubule was estimated to be $503 \mu \mathrm{g} / \mathrm{g}$ using a semiquantitative evaluation.
\end{abstract}

\section{Introduction}

$\mathrm{X}$-ray microscopy with a total-external-reflection mirror optics is an attractive technique for X-ray fluorescence (XRF) analysis using synchrotron radiation because mirrors are achromatic and give relatively high-brilliance beams compared to other focusing elements. Suzuki et al. have successfully developed a total-external-reflection mirror system for microfocusing in the X-ray energy range of 30$100 \mathrm{keV}$ at SPring-8 [1]. They have obtained a focused spot of less than $1 \mu \mathrm{m}$ below X-ray energies of $90 \mathrm{keV}$ using a $200 \mathrm{~m}$ long beamline. Further focusing tests have proved that the mirror system had excellent performance in the highenergy X-ray region and enables not only microscopy but also spectroscopic analysis with sub-micron resolution for high- $Z$ elements.

The need for heavy element analysis has been greatly increasing by the importance of heavy metal accumulation in living organisms. High-energy X-rays $(>20 \mathrm{keV})$ enable direct detection of $\mathrm{K}$ lines from high- $Z$ elements. Nakai et al. have carried out XRF analysis of trace rare-earth and heavy elements using $116 \mathrm{keV}$ X-rays at SPring-8 [2]. They pointed out the advantage of high-energy X-rays for bulk analysis and confirmed that the minimum detection limit (MDL) of the heavy elements was at the sub-ppm level. More recently, microbeam analysis is required for sub-cellularlevel measurements of elemental distributions with highenergy X-rays. Among the problems of the greatest interest are health effects of uranium on populations. For example, environmental contamination in uranium-polluted areas is continuing to rise and uranium can have serious health impacts, such as renal toxicity. Total-external-reflection mirror optics developed by Suzuki et al. [1] is one of the most appropriate focusing systems to enable the analysis of trace heavy elements. In this study, the application of a highenergy scanning X-ray microprobe to evaluate the uranium distribution in rat kidneys is described.

\section{Experimental}

2.1. X-Ray Focusing Optics. The basic design of elliptic Kirkpatrick-Baez optics is essentially the same as that 


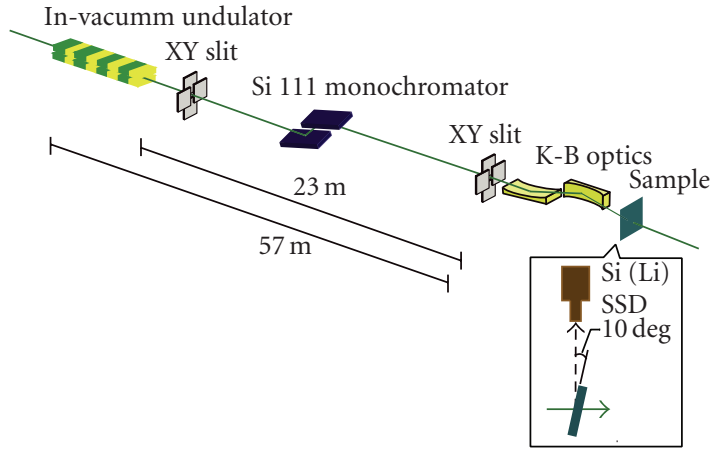

FIGURE 1: Schematic diagram of experimental setup at BL37XU of SPring-8.

described in our previous study [1]. Parabolic mirrors were fabricated by the bent-polished method at Cannon Co. Ltd., Japan $[3,4]$. The mirror material was fused quartz with a thickness of $13 \mathrm{~mm}$. The reflective surface was coated by platinum with a thickness of $1000 \AA$, and the average glancing angle was $0.8 \mathrm{mrad}$. The focal length was $250 \mathrm{~mm}$ for the vertical focusing mirror and $100 \mathrm{~mm}$ for the horizontal focusing mirror.

The experiments were carried out on undulator beamline $37 X U$ of SPring-8 [5]. A schematic diagram of microfocusing optics is illustrated in Figure 1. X-rays from an undulator were monochromatized by a Si 111 double-crystal monochromator with a rotated-inclined crystal geometry [6]. The first crystal employed a pin-post design to enhance the water cooling efficiency. The focusing optics was located $57 \mathrm{~m}$ from the light source. The effective length of each mirror was about $80 \%$ of full length for focal length of $250 \mathrm{~mm}$ and about $65 \%$ for focal length of $100 \mathrm{~mm}$, respectively. It is thought that these effective lengths were limited by the relatively large figure errors at the either end of the mirrors. The illuminating beam size was determined by an aperture size of an XY slit in front of the mirror (slit size: $64 \mu \mathrm{m} \times 52 \mu \mathrm{m}$ ), and only the center area of the mirror was illuminated.

2.2. Scanning X-Ray Microprobe and Application for Biological Specimen. The K-B microfocusing optics was used for a scanning fluorescence X-ray microprobe system. Samples were mounted on an $\mathrm{X}-\mathrm{Y}$ translation stage, and a takeoff angle of $10^{\circ}$ was usually used for detecting fluorescence $\mathrm{X}$-rays from the samples. The fluorescence X-rays were measured by $\mathrm{Si}(\mathrm{Li})$ solid state detector which was placed perpendicular to the incident beams to minimize the scattered $\mathrm{X}$-rays. Figure 1 also shows this geometry.

Calibration standards with various known concentrations of uranium $(20-100 \mu \mathrm{g} / \mathrm{g})$ were used to determine sensitivities and to calibrate intensity levels. These standards were prepared by mixing standard solutions with a polyvinyl alcohol solution. The mixed sample solutions were frozen and then were cut into $20 \mu \mathrm{m}$ sections with a cryomicrotome. Thin sections of kidneys of adult rats were prepared by using the procedure described in [7]. The rats were exposed to uranium $(1.4 \mathrm{mg} / \mathrm{kg})$ by subcutaneous injection. The animals were treated and handled in accordance with the guidelines of the "Guide for the Care and Use of Laboratory Animals at the National Institute of Radiological Sciences". Two days after the administration of uranium, the kidneys were removed and then embedded in an optimal cutting temperature compound to prepare dried sections with $20 \mu \mathrm{m}$ thickness. All sections placed on polypropylene film were fixed on an acrylic holder.

\section{Results and Discussion}

3.1. Performance Test of X-Ray Focusing Elements. The evaluation of focused beam profiles was out with a dark-field knife-edge scan [8] to obtain more accurate beam profiles than with a conventional knife-edge scan. The intensity of the incident and transmitted X-rays were measured by ionization chambers. A tantalum blade with a thickness of $3 \mathrm{~mm}$ was used as the knife edge. To satisfy the dark-field condition, a blade placed between focal point and the detector blocks the direct beam. The detector can feel only the scattered X-rays from the knife edge. The focused profiles at an X-ray energy of $30 \mathrm{keV}$ are shown in Figure 2. The focused beam size of $1.0 \mu \mathrm{m}(\mathrm{V}) \times 0.83 \mu \mathrm{m}(\mathrm{H})$ full width at half maximum (FWHM) is obtained. Here, it is useful to consider the theoretical focused beam size to evaluate the experimentally measured beam size. The actual source size in vertical direction can assume same size of electron beam, which is $15.8 \mu \mathrm{m}$. The horizontal source size is defined by an $\mathrm{XY}$ slit placed at $34 \mathrm{~m}$ from the light source, and the slit width is set to be $200 \mu \mathrm{m}$. Using the focal length of the mirrors, the distance between the light source and the mirrors, and the actual source size, the geometrical focused beam size is calculated to be $0.096 \mu \mathrm{m}(\mathrm{V}) \times 0.87 \mu \mathrm{m}(\mathrm{H})$. On the other hand, according to the literature [1], the diffraction-limited spot size was $0.13 \mu \mathrm{m}(\mathrm{V}) \times 0.04 \mu \mathrm{m}(\mathrm{H})$ at $30 \mathrm{keV}$. The measured beam size in the horizontal direction is near the geometrical beam size $(0.87 \mu \mathrm{m})$. However, the beam size in the vertical direction is significantly larger than the geometrical beam size $(0.096 \mu \mathrm{m})$. This difference is believed to arise from the spread of the beam size in the vertical direction due mainly to the vibration and distortion of the monochrometer crystals. The total photon flux of the focused beam is about $5 \times 10^{9}$ photons $/ \mathrm{s}$ at $30 \mathrm{keV}$.

3.2. Uranium Distribution of a Rat Kidney. Using the focused beam described in the previous section, the quantitative determination of uranium is considered by a calibration curve technique. The obtained calibration curve measured at $30 \mathrm{keV} \mathrm{X}$-rays is shown in Figure 3. The data shows good linearity between a uranium concentration of 100 and $20 \mu \mathrm{g} / \mathrm{g}$. This technique using thin standards has been discussed and validated as the quantitative analysis with microbeam for biological specimens [9]. The MDL is expressed as

$$
\mathrm{MDL}=3 *\left(\frac{C}{I_{N}}\right) *\left(\frac{I_{B}}{t}\right)^{1 / 2},
$$




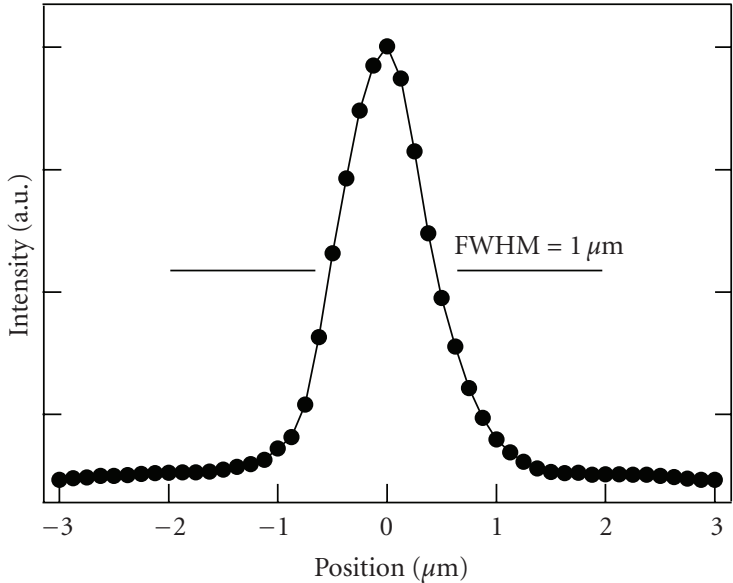

(a)

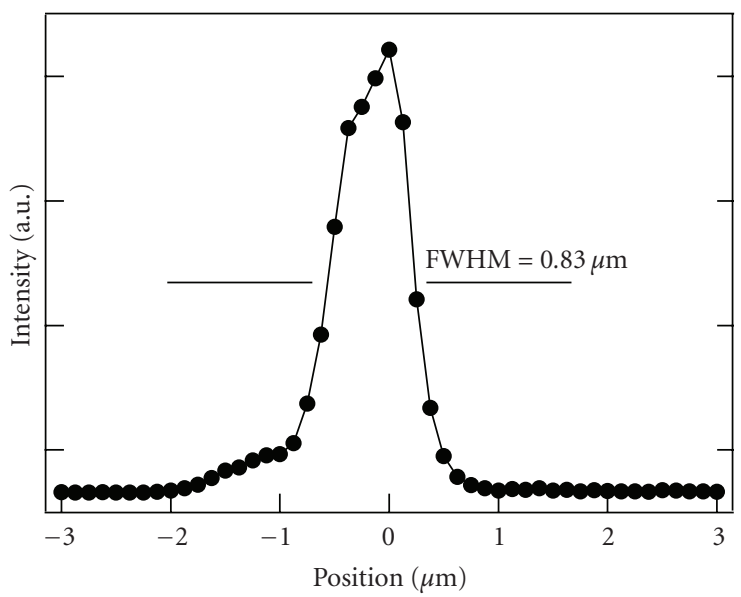

(b)

Figure 2: Measured profiles of focused beam at an X-ray energy of $30 \mathrm{keV}$ using dark-field knife-edge scan. (a) Beam profile in the vertical direction (focal length $=250 \mathrm{~mm}$ ) and (b) beam profile in the horizontal direction (focal length $=100 \mathrm{~mm}$ ).

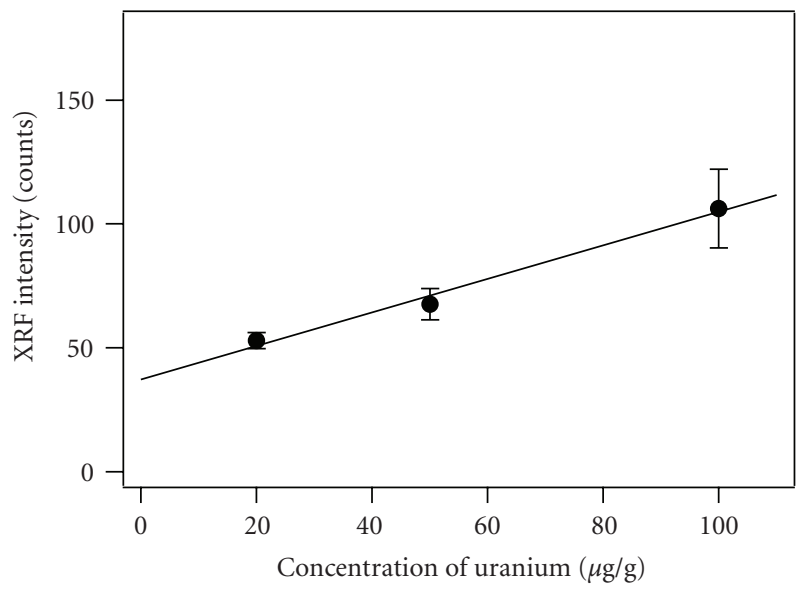

FIgUre 3: Calibration curve for the determination of uranium. The $\mathrm{XRF}$ intensity was plotted against the uranium concentration.

where $C$ is the concentration of uranium $(\mu \mathrm{g} / \mathrm{g}), I_{N}$ is the net intensity (number of counts), $I_{B}$ is the background intensity (number of counts) and $t$ is the counting time (10s) [10]. To quantitatively evaluate the uranium concentration, $5 \times$ 5 raster scans of the each standards were performed. For example, relative standard deviation, which is calculated by dividing the standard deviation by the mean value, of the total XRF intensity of uranium was $12 \%$ at concentration of $20 \mu \mathrm{g} / \mathrm{g}$. According to (1), the estimated MDL value at the lowest end is $10 \mu \mathrm{g} / \mathrm{g}$. These results suggest that the system allows us to quantitatively analyze heavy trace elements in biological samples even with microbeam resolution.

Prior to the $\mu$-XRF imaging of the samples, XRF imaging with beam size of $200 \mu \mathrm{m} \times 200 \mu \mathrm{m}$ was performed to determine the overall elemental distribution in the renal sections at X-ray energy of $30 \mathrm{keV}$. Figure 4 shows the distribution of iron, zinc, and uranium in the kidney. The intensity of the XRF images is shown as the color scale from blue to white, which corresponds to the XRF intensity from lowest to highest. Although an XRF image of uranium is usually measured by detecting an $U L_{\alpha}$ line $(13.6 \mathrm{keV})$, here, $U L_{\beta}$ lines $\left(L_{\beta 1}: 17.2 \mathrm{keV}, L_{\beta 2}: 16.4 \mathrm{keV}\right)$ are measured to avoid overlapping by rubidium $K_{\alpha}$ line $(13.4 \mathrm{keV})$ because of the existence of rubidium in the rat kidney [11]. Iron was localized to the inner stripe of the outer medulla (Figure 4(b)), while the zinc was distributed equally in the cortex and in the outer stripe of the outer medulla than the inner stripe of the outer medulla (Figure 4(c)). In contrast to the normal elements, uranium shows a completely different distribution. The uranium was localized only in the outer stripe of the outer medulla (Figure 4(d)). To get more detailed information about uranium distributions, high resolution $\mu$-XRF imaging in the highly localizing area marked in Figure 4(d) was carried out at the X-ray energy of $37 \mathrm{keV}$. The twodimensional distribution of uranium is shown in Figure 5(a). The shape of the proximal tubule is obviously visualized by the uranium distribution. Figure 5(b) represents an XRF spectrum measured at the point indicated by an arrow head in Figure 5(a). It is observed that the uranium $L_{\beta}$ lines can be clearly detected without interference from other elements. Uranium concentrations for the image were calculated using the calibration curve showed in Figure 3. However, a corrected calibration curve was used for estimating the uranium concentration because of different excitation energy between Figure $3(30 \mathrm{keV})$ and Figure $5(37 \mathrm{keV})$. Assuming the matrix density and thickness between the samples and standards have approximately the same value, we considered only the correction for the linear absorption coefficients of 30 and $37 \mathrm{keV} \mathrm{X}$-rays. The model linear absorption coefficients of uranium were $763 \mathrm{~cm}^{-1}$ at $30 \mathrm{keV}$, and $442 \mathrm{~cm}^{-1}$ at $37 \mathrm{keV}$, respectively. These coefficients were provided from the NIST physical reference data [12]. Though this correction is only approximately, it is expected that the calculated values give a semiquantitative map of the uranium concentration. 


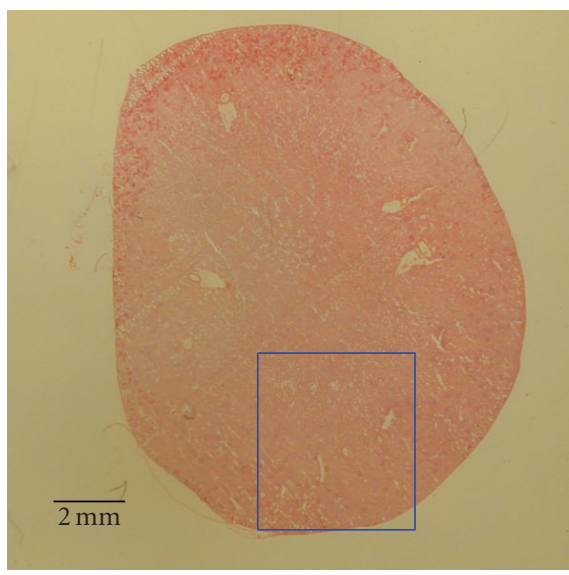

(a)

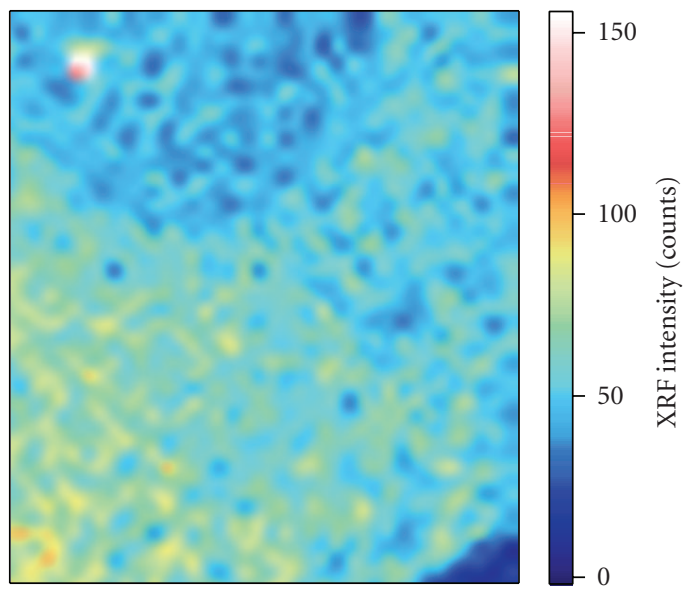

(c)

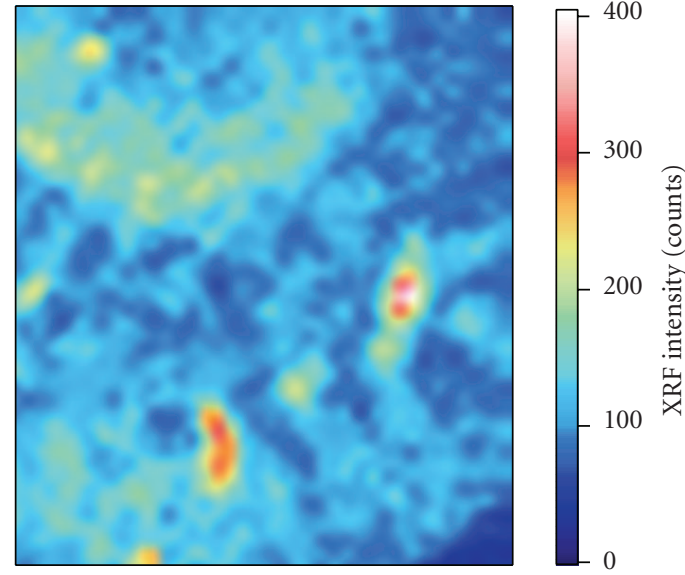

(b)

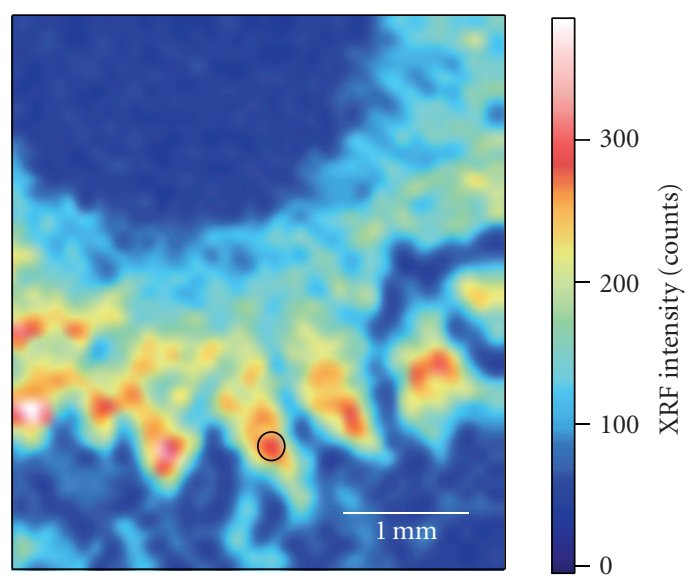

(d)

FIGURE 4: XRF imaging of a renal cross section. (a) photograph of a serial section showing the imaging area. The two-dimensional distribution of (b) iron, (c) zinc, and (d) uranium. Beam size: $200 \mu \mathrm{m}(\mathrm{V}) \times 200 \mu \mathrm{m}(\mathrm{H})$, imaging area: $4.5 \mathrm{~mm}(\mathrm{~V}) \times 4 \mathrm{~mm}(\mathrm{H})$, pixel size: $100 \mu \mathrm{m}$, and dwell time: $5 \mathrm{~s}$.

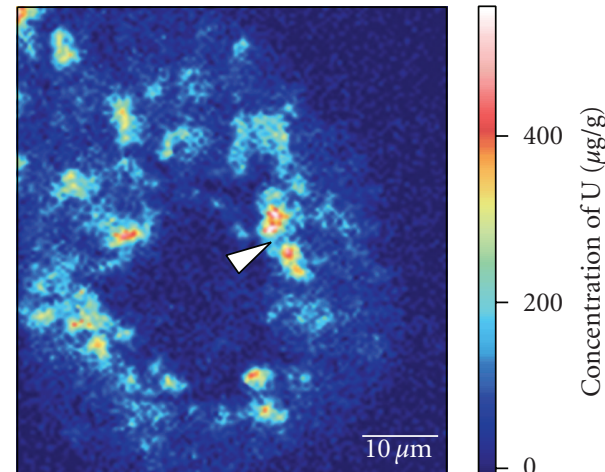

(a)

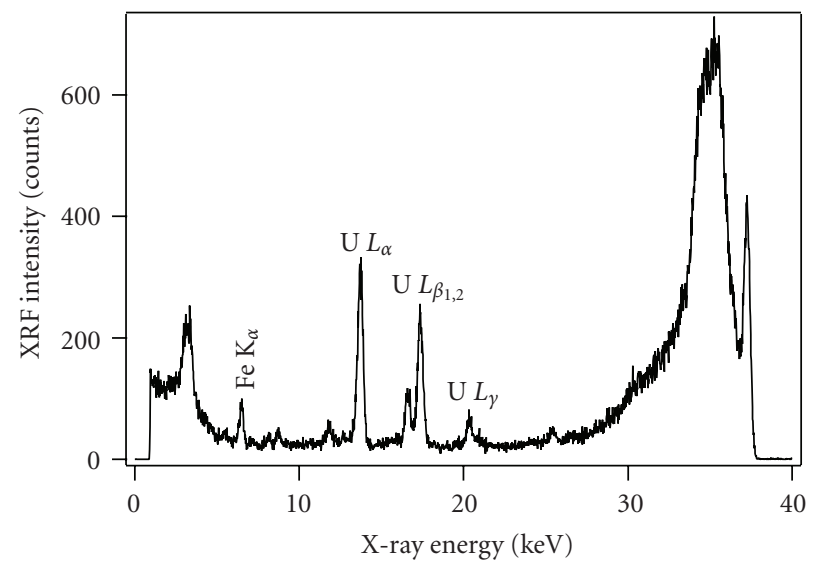

(b)

Figure 5: High resolution $\mu$-XRF image of the marked area in Figure 4(d) measured at $37 \mathrm{keV}$ X-rays. (a) The two-dimensional distribution of uranium. The XRF intensities are estimated to the concentration of uranium. Beam size: $1.2 \mu \mathrm{m}(\mathrm{V}) \times 1.4 \mu \mathrm{m}(\mathrm{H})$, imaging area: $75 \mu \mathrm{m}$ (V) $\times 57 \mu \mathrm{m}(\mathrm{H})$, pixel size: $0.5 \mu \mathrm{m}$, and dwell time: $5 \mathrm{~s}$. (b) X-ray fluorescence spectrum at arrow head in Figure 5 (a). Measurement time is $600 \mathrm{~s}$. 
The maximum concentration of uranium in the tubule was estimated to be $503 \mu \mathrm{g} / \mathrm{g}$ by using the assumptions above. The quantified value is about 23 times higher than the mean concentration in the kidney $(22.3 \mu \mathrm{g} / \mathrm{g}$ wet weight at 2 days measured by inductively-coupled plasma mass spectrometry). This intense localization is in good agreement with a previous study [7]. The elemental imaging indicated that uranium is selectively distributed in the proximal tubules and highly concentrated in the epithelium of the tubules.

\section{Conclusion}

A scanning fluorescence $\mathrm{X}$-ray microprobe with sub-micron transverse spatial resolution was achieved at beamline 37XU of SPring-8 using total-external-reflection K-B mirror optics. A focused beam size of $1.0 \mu \mathrm{m}(\mathrm{V}) \times 0.83 \mu \mathrm{m}(\mathrm{H}) \mathrm{FWHM}$ at the X-ray energy of $30 \mathrm{keV}$ was achieved. The mirror optics provides sufficient spatial resolution to examine $\mu$-XRF analysis of high- $Z$ elements even with high-energy X-rays. The quantitative evaluation of $\mu$-XRF analysis was performed by a calibration-curve method. The MDL with a beam size of around $1 \mu \mathrm{m}^{2}$ was $10 \mu \mathrm{g} / \mathrm{g}$. The X-ray microprobe was also utilized to map the uranium distribution in the kidneys of rats exposed to uranium acetate. It was revealed that uranium localized in the proximal tubule with a 23 times higher concentration compared to the whole kidney. These results provide useful information to understanding the chemical and radiological toxicity of uranium in the kidney. This technique will contribute greatly to understand dynamic mechanism of trace high- $Z$ elements with submicron resolution and will open new application for a variety of fields using XRF analysis.

\section{Acknowledgments}

This study has been performed under the approval of Japan Synchrotron Radiation Research Institute (JASRI) as Nanotechnology Support Project of the Ministry of Education, Culture, Sports, Science, and Technology (Proposal no. 2008A1662/BL37XU). A part of the experiments also has been carried out under the approval of SPring-8 Proposal Review Committee (Proposal no. 2007A1392).

\section{References}

[1] Y. Suzuki, A. Takeuchi, and Y. Terada, "High-energy X-ray microbeam with total-reflection mirror optics," Review of Scientific Instruments, vol. 78, no. 5, Article ID 053713, 3 pages, 2007.

[2] I. Nakai, Y. Terada, M. Itou, and Y. Sakurai, "Use of highly energetic $(116 \mathrm{keV})$ synchrotron radiation for X-ray fluorescence analysis of trace rare-earth and heavy elements," Journal of Synchrotron Radiation, vol. 8, no. 4, pp. 1078-1081, 2001.

[3] A. Takeuchi, Y. Suzuki, H. Takano, and Y. Terada, "Kirkpatrick-Baez type X-ray focusing mirror fabricated by the bent-polishing method," Review of Scientific Instruments, vol. 76, no. 9, Article ID 093708, 4 pages, 2005.
[4] A. Takeuchi, Y. Suzuki, and H. Takano, "X-ray focusing mirror fabricated with bent-polishing method," in Proceedings of the 18th International Conference on Synchrotron Radiation Instrumentation, vol. 705 of AIP Conference Proceedings, pp. 760-763, San Francisco, USA, 2004.

[5] Y. Terada, S. Goto, N. Takimoto, et al., "Construction and commissioning of BL37XU at SPring-8," in Proceedings of the 18th International Conference on Synchrotron Radiation Instrumentation, vol. 705 of AIP Conference Proceedings, pp. 376-379, San Francisco, USA, 2004.

[6] M. Yabashi, H. Yamazaki, K. Tamasaku et al., "SPring-8 standard X-ray monochromators," in X-Ray Optics Design, Performance, and Applications, vol. 3773 of Proceedings of SPIE, pp. 2-13, Denver, Colo, USA, July 1999.

[7] S. Homma-Takeda, Y. Terada, A. Nakata et al., "Elemental imaging of kidneys of adult rats exposed to uranium acetate," Nuclear Instruments and Methods in Physics Research Section B, vol. 267, no. 12-13, pp. 2167-2170, 2009.

[8] Y. Suzuki, A. Takeuchi, H. Takano, and H. Takenaka, "Performance test of fresnel zone plate with $50 \mathrm{~nm}$ outermost zone width in hard X-ray region," Japanese Journal of Applied Physics, vol. 44, no. 4A, pp. 1994-1998, 2005.

[9] S. Homma-Takeda, Y. Nishimura, H. Iso, T. Ishikawa, H. Imaseki, and M. Yukawa, "A new approach for standard preparation in microbeam analysis: development and validation," Journal of Radioanalytical and Nuclear Chemistry, vol. 279, no. 2, pp. 627-631, 2009.

[10] C. J. Sparks, "X-ray fluorescence microprobe for chemical analysis," in Synchrotron Radiation Research, H. Winick and S. Doniach, Eds., pp. 459-512, Plenum Press, New York, NY, USA, 1980.

[11] S. Homma-Takeda, Y. Terada, H. Iso, et al., "Rubidium distribution in kidneys of immature rats," International Journal of PIXE, vol. 19, no. 1-2, pp. 39-45, 2005.

[12] "X-ray Form Factor, Attenuation, and Scattering Tables database," http://physics.nist.gov/PhysRefData/FFast/html/form .html. 